\title{
Long non-coding RNAs of switchgrass (Panicum virgatum L.) in multiple dehydration stresses
}

\author{
Chao Zhang ${ }^{1,2+}$, Gaijuan Tang ${ }^{3 \dagger}$, Xi Peng ${ }^{1}$, Fengli Sun ${ }^{1,2^{*}}$, Shudong Liu ${ }^{1,2}$ and Yajun $\mathrm{Xi}^{1,2^{*}}$
}

\begin{abstract}
Background: Long non-coding RNAs (IncRNAs) play important roles in plant growth and stress responses. Studies of IncRNAs in non-model plants are quite limited, especially those investigating multiple dehydration stresses. In this study, we identified novel IncRNAs and analyzed their functions in dehydration stress memory in switchgrass, an excellent biofuel feedstock and soil-conserving plant in the Gramineae family.
\end{abstract}

Results: We analyzed genome-wide transcriptional profiles of leaves of 5-week-old switchgrass plantlets grown via tissue culture after primary and secondary dehydration stresses (D1 and D2) and identified 16,551 novel IncRNAs, including 4554 annotated IncRNAs (targeting 3574 genes), and 11,997 unknown IncRNAs. Gene ontology and pathway enrichment analysis of annotated genes showed that the differentially expressed IncRNAs were related to abscisic acid $(\mathrm{ABA})$ and ethylene $(\mathrm{ETH})$ biosynthesis and signal transduction, and to starch and sucrose metabolism. The upregulated IncRNAs and genes were related to ABA synthesis and its signal transduction, and to trehalose synthesis. Meanwhile, IncRNAs and genes related to ETH biosynthesis and signal transduction were suppressed. LncRNAs and genes involved in $A B A$ metabolism were verified using quantitative real-time $P C R$, and the endogenous $A B A$ content was determined via high performance liquid chromatography mass spectrometry (HPLC-MS). These results showed that ABA accumulated significantly during dehydration stress, especially in D2. Furthermore, we identified 307 dehydration stress memory IncRNAs, and the ratios of different memory types in switchgrass were similar to those in Arabidopsis and maize.

Conclusions: The molecular responses of switchgrass IncRNAs to multiple dehydration stresses were researched systematically, revealing novel information about their transcriptional regulatory behavior. This study provides new insights into the response mechanism to dehydration stress in plants. The IncRNAs and pathways identified in this study provide valuable information for genetic modification of switchgrass and other crops.

Keywords: Switchgrass (Panicum virgatum L.), Biomass and biofuel, Dehydration stress, Transcriptional profiles, Abscisic acid, Dehydration stress memory

\section{Background}

Drought stress is one of the most widespread and harmful abiotic stresses; it includes atmospheric drought and soil drought. Both of these drought types lead to dehydration stress in plants. Under natural conditions, plants suffer thousands of dehydration stresses throughout their lifecycle, and may even experience multiple stresses over a few days. To deal with this situation, plants have evolved

\footnotetext{
*Correspondence: sunof1981@126.com; xiyajun2002@126.com

${ }^{\dagger}$ Equal contributors

${ }^{1}$ College of Agronomy, Northwest A \& F University, Yangling 712100,

Shaanxi, China

Full list of author information is available at the end of the article
}

dehydration stress memory, which has been identified in Arabidopsis [1, 2], maize [3], and other species [4-7]. Using this ability, plants can respond rapidly and strongly to dehydration stress and thus improve their survival rates. The formation of dehydration stress memory involves chromatin methylation (especially histone methylation, such as trimethylation of histone $\mathrm{H} 3$ on lysine 4, H3K4me3) [2, 8, 9], plant hormone biosynthesis, and signal transduction [2, 10, 11]. In the Arabidopsis genome, distinct regions were found to be susceptible to DNA (de) methylation in response to hyperosmotic stress, and long non-coding RNAs (lncRNAs) regulate the expression of targeted genes in response to stress [12, 13]. Furthermore,

(c) The Author(s). 2018 Open Access This article is distributed under the terms of the Creative Commons Attribution 4.0 International License (http://creativecommons.org/licenses/by/4.0/), which permits unrestricted use, distribution, and 
animal lncRNAs can interact with trithorax group proteins via $\mathrm{H} 3 \mathrm{~K} 4 \mathrm{me} 3$ and positively regulate transcription activity $[14,15]$. Therefore, we infer that lncRNAs likely have important functions in dehydration stress memory and regulating the responses to multiple dehydration stresses.

LncRNAs are a type of non-coding RNA that are at least $200 \mathrm{nt}$ in length, including natural antisense transcripts, long intronic non-coding RNAs, and long intergenic noncoding RNAs (lincRNAs) [16]. Among plants, a large number of IncRNAs have been found in Arabidopsis [17-20], maize [21], wheat [22], rice [23], and other species [24, 25]. LncRNAs play roles in plant growth and development [23, 26-28], biotic stress responses [18, 29, 30], and abiotic stress responses [21, 31, 32]. For example, 2224 lncRNA candidates were discovered in rice, one of which was confirmed to play a role in panicle development and fertility [23]. LncRNA-regulated photoperiod-sensitive male sterility has also been discovered in rice [26]. In Arabidopsis, 2708 expressed lincRNAs [20] and 20 Fusarium oxysporumresponsive lncTARs (long non-coding transcriptionally active regions) were identified [18], with 245 poly(A) + and 58 poly(A) - IncRNAs differentially expressed under various stress stimuli (drought, salinity, cold, and heat) [17]. Aside from Arabidopsis [33] and rice, stress-responsive lncRNAs have also been identified in cotton [25], maize [21], wheat [22], and Medicago truncatula [31].

Although numerous IncRNAs have been identified and some of their functions have been described, research in non-model plants has been very limited. The mechanism of IncRNA regulation and its function in dehydration stress are unclear, especially under repetitive dehydration stress conditions. Investigation, functional prediction, and dissection of lncRNAs in response to multiple dehydration stresses will be beneficial for understanding the process of dehydration stress memory, as well as for uncovering the functions and regulatory mechanisms of lncRNAs.

Switchgrass is a perennial, drought-resistant C4 grass in the Gramineae family [34, 35]. It is grown worldwide as an important lignocellulosic biofuel feedstock, soilconserving plant, and pasture crop [35-37]. Common switchgrass has two ecotypes: the lowland ecotype (tetraploid) and upland ecotype (hexaploid and octoploid) [38]. These ecotypes are allogamous and have strong genetic self-incompatibility, which seriously limits research into biofuel production and stress resistance. In a previous study, we established an in vitro tissue culture system [39]. Using this system, large-scale production of homogenous switchgrass plantlets with a single genotype was carried out from the axillary buds of a single plant. The use of tissue culture avoids the unreliability of crosspollination and will facilitate future studies of switchgrass.

To date, the majority of studies into drought stress responses of switchgrass are related to its morphological and physiological responses, while the studies on molecular mechanisms of drought resistance have been very limited. Under drought stress, switchgrass improved its drought tolerance by increasing the levels of reactive oxygen species induced by abscisic acid (ABA), causing the water potential, gas exchange rate, and photochemical processes in leaves to decline significantly $[40,41]$. Assessment of drought resistance in 49 switchgrass genotypes suggested that drought-tolerant genotypes tend to have higher levels of $\mathrm{ABA}$, spermine, trehalose, and fructose [42]. Furthermore, microRNAs that respond to drought stress were discovered, which were involved in the biosynthesis of carbon compounds, glucose, starch, fatty acids, and lignin [43, 44].

ABA biosynthesis and signal transduction is the key pathway of the drought stress response, involving stomatal closure and osmotic adjustment [45, 46]. In Arabidopsis, 9cis-epoxycarotenoid dioxygenase (NCED) catalyzes the rate-limiting step of the ABA biosynthesis pathway [47], and the signal transduction elements include the PYR/PYL receptor, protein phosphatase $2 \mathrm{C}$ (PP2C), serine/threonineprotein kinase SRK (SnRK), and ABA-responsive element binding factors (AREBs/ABFs) [48, 49].

LncRNA can play its role through regulating the transcription machinery, as it can directly regulate the Pol II transcription machinery in various ways [15]. LncRNAs located upstream or downstream of genes may interact with promoters, cis-acting elements, or other regulatory factors, and thus regulate gene transcription [50-52]. Meanwhile, lncRNA may be involved in gene silencing, transcription, and mRNA stability through complementary base-pairing with the sense strand of mRNA [53]. At present, switchgrass IncRNAs have not been identified, and their functions in drought stress, and especially in repeated drought stress, are unknown.

In this study, switchgrass plantlets of a homogeneous genotype were used for transcriptional and physiological assays. We identified 16,551 novel lncRNAs, and annotated 4554 lncRNAs expressed during multiple dehydration stresses. Functional analysis of the target genes of differentially expressed lncRNAs indicated that the pathways with key roles in repeated dehydration stress response include $\mathrm{ABA}$ and ethylene biosynthesis, signal transduction, and starch and sucrose metabolism. These pathways were confirmed using orthologous alignment, quantitative real-time PCR, and chemical assays. Furthermore, we identified dehydration stress memory lncRNAs, and compared dehydration stress memory behaviors among Arabidopsis, maize, and switchgrass.

\section{Methods}

Plant materials and experimental design

Switchgrass is allogamous plant with strong genetic selfincompatibility. To avoid differences among seedling genotypes, plantlets developed through in vitro tissue culture 
were used in this study. They were acquired from a single bud of the Alamo cultivar (introduced from the USA) grown in MS medium supplemented with $13.3 \mu \mathrm{M} \cdot \mathrm{L}^{-1} 6$ benzylaminopurine [39]. Multiple dehydration stresses were induced based on designs used previously with Arabidopsis $[1,2]$ and maize [3]. Five-week-old plantlets were removed from the soil, washed of residual substrate, and acclimated overnight in an incubator at constant temperature and humidity with their roots in water. The next morning, the plantlets were removed, patted dry on filter paper, and then air-dried for $2 \mathrm{~h}$ (the first dehydration stress, D1). The plantlets under normal conditions were sampled as a control (C1). D1 plants were then placed in a 22-h recovery treatment at $25{ }^{\circ} \mathrm{C}$ (first recovery, R1), and R1 plants were subsequently air-dried for $2 \mathrm{~h}$ and sampled as the second dehydration stress (D2). These procedures were repeated for R2, D3, etc. (Fig. 1a). To investigate the altered expression of lncRNAs/genes, we sequenced the non-coding RNAs and mRNAs of leaves, and determined the transcriptional expression by qRT-PCR. At morphophysiology level, we determined leaf water loss and endogenous ABA contents in different treatments (Fig. 1a).

\section{RNA isolation, IncRNA and mRNA library construction}

The second fully expanded leaves of plants were collected, frozen immediately in liquid nitrogen and stored at $-80{ }^{\circ} \mathrm{C}$ for RNA extraction and physiological and biochemical assays. Total RNA was isolated and purified using Trizol reagent (Invitrogen Life Technologies, USA) and RNase-Free DNase I (Takara, 2270A) following a published protocol [54]. RNA concentration was detected using a Qubit fluorometer and a NanoDrop One spectrophotometer (Thermo Scientific, USA), OD260/ 280 and OD260/230 (absorbances under $260 \mathrm{~nm}$, $280 \mathrm{~nm}$, and $230 \mathrm{~nm}$ ultraviolet light) were detected via a NanoDrop One spectrophotometer, and the RNA integrity (RIN) was measured with an Agilent 2100 bioanalyzer (Agilent Technologies, USA). Two biological replicates of four treatments $(\mathrm{C} 1, \mathrm{D} 1, \mathrm{R} 1$, and $\mathrm{D} 2)$ were sequenced, for a total of eight samples. RNA sequencing
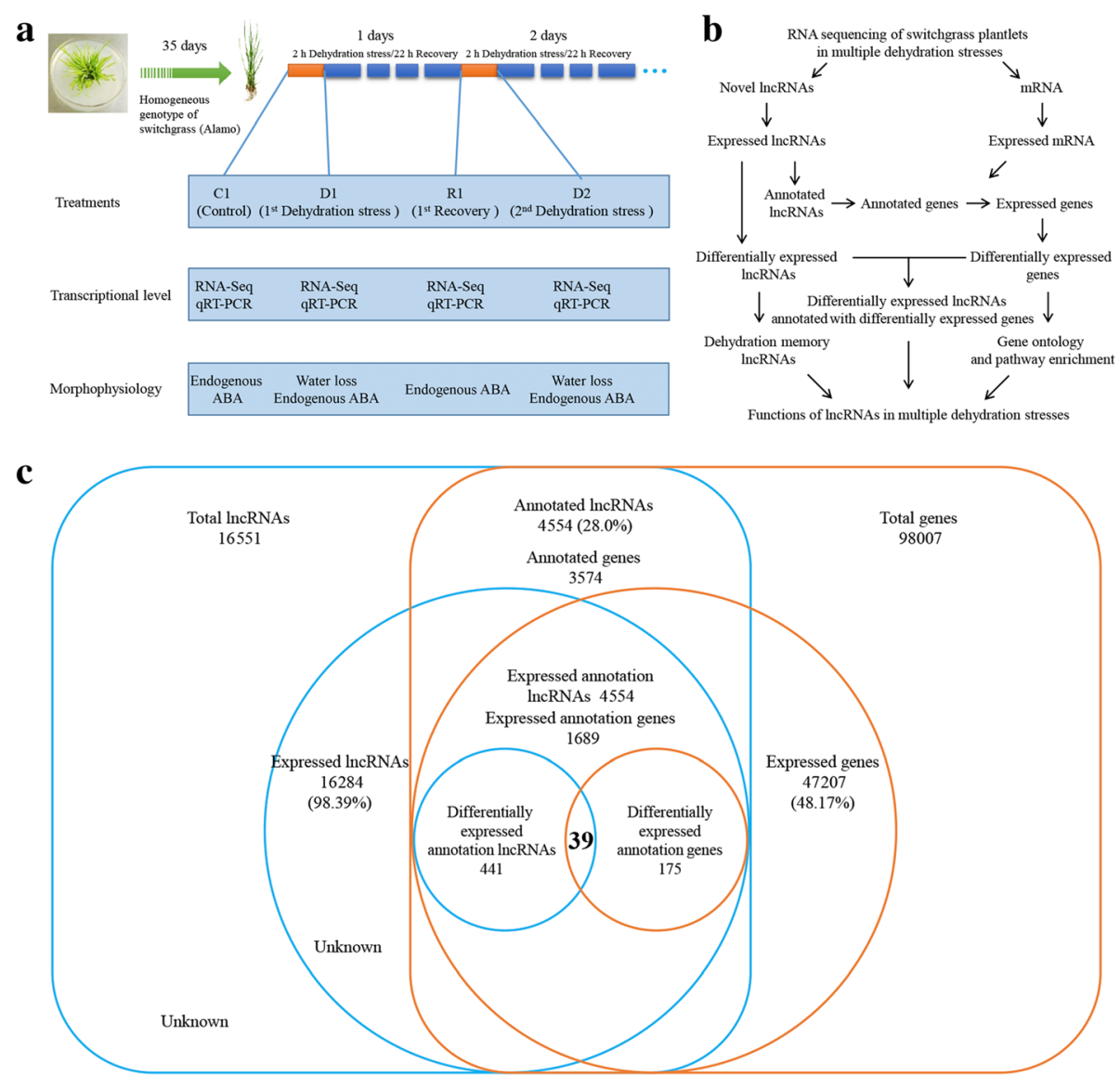

Fig. 1 Experimental design and analysis procedures for the systematic identification of IncRNAs in switchgrass. a Experimental design for repeated dehydration stresses and sample collection. b Functional analysis procedures of IncRNAs in multiple dehydration stresses. $\mathbf{c}$ Identification and annotation of differentially expressed IncRNAs and annotated genes. ABA, endogenous abscisic acid content; C, control; D1-2, the first and second third dehydration stresses; R1, the first recovery periods; RNA-Seq, RNA-Sequencing; qRT-PCR, quantitative real-time PCR 
(RNA-seq) was performed by the BGI-Shenzhen Company (http://www.genomics.cn/en/) using the Illumina GAII platform (HiSeq2500), and lncRNA and mRNA libraries were constructed. To remove adapter sequences and low quality sequences, the raw data was filtered using SOAP software (http://soap.genomics.org.cn/) with the default parameters. Gene and lncRNA expression levels were calculated as FPKM (Fragments Per Kilobase of exon per Million fragments mapped) values using the Cufflinks program [55]. RNA-seq quality and the repeatability of biological replicates are shown in Additional file 1: Figure S1. The raw sequencing files of transcriptomic data were uploaded to the NCBI sequence read archive (SRA) under accession number PRJNA394165.

\section{Identification of differential expression of genes and IncRNAs}

Genes and lncRNAs were predicted based on the switchgrass genomic database (https://phytozome.jgi.doe.gov/ pz/portal.html\#!info?alias=Org_Pvirgatum) [56]. Differentially expressed genes and lncRNAs were identified using the following threshold values: $q$ value $\leq 0.05$ and | $\log$ (base2) fold change $\mid \geq 1$ with the Cuffdiff tool in the Cufflinks package (http://cole-trapnell-lab.github.io/cufflinks/) [55]. Common and differentially expressed genes and IncRNAs in various samples were compared and identified using Venny 2.1 software (http://bioinfogp. cnb.csic.es/tools/venny/index.html).

Dehydration stress memory lncRNAs were identified using methods published for Arabidopsis and maize [1, 3]. They were identified by comparison of fold changes in expression between D1/C1 and D2/D1, using threshold values of $q$ value $\leq 0.05$ and $\mid \log$ (base2) fold change $\mid \geq 1$. LncRNAs that were upregulated, downregulated, and those that exhibited no significant change in expression are indicated by the symbols "+", "-" and "=", respectively. Eight types of differentially expressed lncRNA were defined: $[+/+],[+/-],[-/+],[-/-],[+/=],[-/=],[=/+]$ and $[=/-]$. The first four types were considered to be dehydration stress memory lncRNAs, because their responses changed between D1 and D2. The $[+/=]$ and $[-/=]$ lncRNAs were considered non-memory lncRNAs, and $[=/+]$ and $[=/-]$ genes were defined as late-response lncRNAs. A list of all identified dehydration stress memory lncRNAs is provided in Additional file 2: Table S1.

\section{Annotation and functional analysis of IncRNAs}

To date, many lncRNAs located upstream or downstream of genes have been identified, which are involved in transcriptional regulation via interaction with promoters, cisacting elements $[50,51]$ or other regulatory functions [52]. Meanwhile, lncRNAs may be involved in gene silencing, transcription, and mRNA stability through complementary base-pairing with the sense strand of mRNA [53]. In this study, lncRNAs were annotated by scanning regions within $2000 \mathrm{bp}$ upstream and downstream of genes, and analyzing the complementary base-pairing between antisense lncRNAs and mRNAs using RNAplex software [57].

Genes targeted by lncRNAs were annotated using NCBI Blast tools (version 2.2.8) in conjunction with the NCBI non-redundant protein sequences (nr) database, the Arabidopsis Information Resource Proteins database (release TAIR10), the maize B73 RefGen_v3 database, and the Rice Genome Annotation Project (RGAP) release 7. All target genes and differentially expressed target genes were analyzed. Gene ontology (GO) was analyzed using AgBase GORetriever and GOSlimViewer [58], and enriched pathways were identified using NCBI Flink (https://www.ncbi. nlm.nih.gov/Structure/flink/flink.cgi) based on KEGG (Kyoto Encyclopedia of Genes and Genomes) databases. Specific pathways were verified using Blastp with the switchgrass genomic database and the TAIR10 database. Orthologous genes belonging to larger families were analyzed with reference to published works.

\section{Quantitative real-time PCR, physiological indices assays and statistical analysis}

Total RNA was reverse-transcribed to cDNA using the PrimeScript RT reagent Kit (RR047A, Takara) following the standard protocol. Quantitative real-time PCR (qRTPCR) was performed with the QuantStudio 7 Flex RealTime PCR System (Thermo Scientific, USA) using the SYBR Premix Ex Taq II Kit (RR820A, Takara). A reported housekeeping gene, PveEF-1 $\alpha$ (eukaryotic elongation factor $1 \alpha$ ) [59], was chosen as a reference gene. Three biological replicates were performed, with each biological replicate having three technical replicates. The $\Delta \Delta C T$ method was used to calculate gene expression levels, and all primers were designed using Primer Premier 6 software (http://www.premierbiosoft.com/primer design/index.html; Additional file 2: Table S2).

To verify the ABA biosynthesis pathway indicated by transcriptomic data, the second fully expanded leaves were collected from four treatments. Endogenous ABA contents were determined using high performance liquid chromatography mass spectrometry (HPLC-MS) with an Agilent 1290 Infinity II liquid chromatograph (Agilent Technologies, USA) and a QTRAP 6500 MS/MS System (AB SCIEX, USA). Reference standards (ABA, LC grade) were purchased from Sigma-Aldrich (USA). The water loss was determined by measuring the leaves' weight at a fixed time interval after their detachment from the plants.

More than three biological replicates were used in all physiological and chemical substance assays. Each biological replicate contained more than 12 plantlets, and only the second fully expanded leaves were utilized for experiments. All data were analyzed with SAS software 
(http://www.sas.com/en_us/software/sas9.html) with the Duncan test [60].

\section{Results}

General features of dehydration stress response IncRNAs Prior to RNA sequencing, we investigated the drought resistance of switchgrass under multiple water-deficit stresses. The results showed that the water loss from leaves during the second and third dehydration stresses was 14.6 and $18.0 \%$ slower than during the first dehydration stress after $24 \mathrm{~h}$ dehydration treatment, and that water-deficit training significantly improved the survival rates of the plantlets (Additional file 1: Figure S2). In this study, we acquired homogeneous switchgrass plantlets through shoot bud culture, extracted the leaf RNAs under repeated dehydration stresses, and constructed a transcriptional database of lncRNA and mRNA (Fig. 1b). The ratio of clean reads in each sample exceeded $96.5 \%$, and the average replication rate of gene expression numbers in two biological replicates was 90.2\% (Additional file 1: Figure S1). For differentially expressed lncRNAs and genes, the average coefficient value between two biological replicates was 99.1\% (Additional file 1: Figure S1), indicating excellent repeatability of the results across biological replicates.

The expression, location, and length of lncRNAs were analyzed in this study. In total, 16,551 lncRNAs and 98,007 genes were predicted, and 16,284 (98.39\%) lncRNAs and 47,207 (48.17\%) genes were expressed during dehydration stress (Fig. 1c; Additional file 2: Table S3). In all eight samples, 11,142 (68.4\%) lncRNAs and 40,545 (85.9\%) genes were expressed. On average, each sample had 19,414 novel transcripts, $38.8 \%$ (7549) of which were novel noncoding transcripts (Additional file 2: Table S3). These transcripts were distributed across all chromosomes, and there were some hot-spots in each chromosome with many enriched transcripts (Fig. 2a). We identified differentially expressed lncRNAs using the threshold values: | $\log$ (base2) fold change $\mid \geq 1, q \leq 0.05$. In total, 1597 differentially expressed lncRNAs were identified under repeated dehydration stresses (Additional file 2: Table S4), and they were distributed across all chromosomes, similar to the distribution of total lncRNAs (Fig. 2b, c). Notably, numerous differentially expressed lncRNAs were found on chromosomes 05b, 02a, and 09b (Fig. 2c). In addition, we counted the frequency of different IncRNA lengths. Our results demonstrated that $53.7 \%$ of lncRNAs were shorter than 800 bp (base pair), and $59.2 \%$ of differentially expressed lncRNAs were shorter than 400 bp (Fig. 2d), suggesting that the lengths of differentially expressed lncRNAs are relatively short.

\section{Annotation and identification of differentially expressed IncRNAs}

LncRNAs located upstream of genes may be involved in transcriptional regulation through interaction with promoters or other cis-acting elements [50, 51], and downstream lncRNAs may take part in other regulatory activities [52]. Similar to the action mode of microRNA, lncRNA may be involved in gene silencing, transcription, and mRNA stability through complementary base-pairing with the sense strand of mRNA [53]. In this study, we annotated lncRNAs by scanning up to 2000 bp upstream and downstream of genes, and analyzing the complementary base-pairing between antisense lncRNAs and mRNAs using RNAplex software [57]. In total, 4554 (28.0\%) lncRNAs were annotated, including 2129 antisense lncRNAs and 2425 upstream or downstream lncRNAs involved with 2018 and 1556 genes, respectively (Additional file 2: Table S5). During multiple dehydration stresses, $47.3 \%(1689)$ of the annotated genes were expressed (Table 1; Fig. 1c). Furthermore, we identified 441 differentially expressed lncRNAs and 175 differentially expressed annotated genes (Additional file 2: Table S6). Among these, 39 lncRNAs were annotated and were differentially expressed genes (Additional file 2: Table S7; Fig. 1c), which probably play important roles in the repeated dehydration stress response. These genes were involved in $\mathrm{ABA}$ and ethylene (ETH) biosynthesis and signal transduction, starch and sucrose metabolism, and other functions. (Additional file 2: Table S7).

\section{GO and pathway enrichment analysis of IncRNA target genes}

GO analysis provided information on the functional categorization of lncRNA target genes. We investigated the functions of all annotated genes and differentially expressed annotated genes. The categories of membrane and intracellular (for cellular components) and transferase activity and catalytic activity (for molecular functions) were enriched in all annotated genes, while plastid and catalytic activity were significantly enriched in differentially expressed genes (Fig. 3a, b). For biological process analysis, the terms of biosynthetic processes, nucleobase-containing compound metabolic processes, and cellular protein modification processes were enriched in all annotated genes as well as in differentially expressed genes, while carbohydrate metabolic processes and translation were enriched only in differentially expressed genes (Fig. 3c). The stress response and signal transduction categories were also enriched (Fig. 3c). We analyzed the GO term 'response to stress', and identified 15 lncRNAs annotated with 15 genes related to ABA and ETH biosynthesis and signal transduction, starch and sucrose metabolism, osmotic adjustment, and other functions. (Additional file 2: Table S8).

To investigate the roles of IncRNA, we analyzed pathways related to antisense genes, upstream and downstream genes, and differentially expressed annotated genes. The 

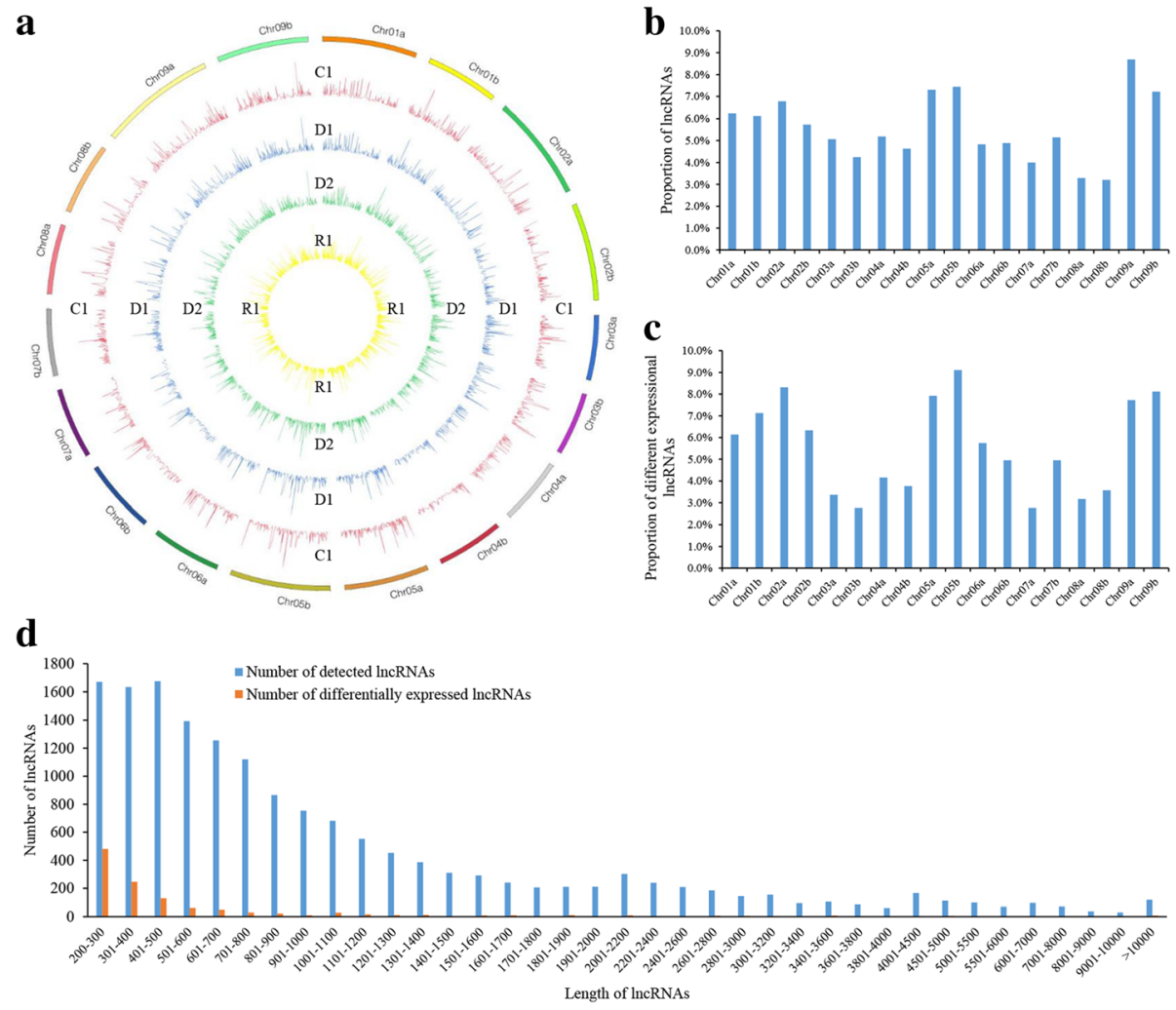

Fig. 2 Characteristics of switchgrass IncRNAs. a The expression level of IncRNAs ( $\log _{10}$ FPKM) along the switchgrass eighteen chromosomes. It comprises four concentric rings, and they are C1, D1, D2 and R1 from outer to inner, respectively. b Distribution of IncRNAs in different chromosomes. c Distribution of differentially expressed IncRNAs in different chromosomes. $\mathbf{d}$ Length distribution of all IncRNAs and differentially expressed IncRNAs. c, control; D1-2, first and second dehydration stresses; R1, first recovery period

common enriched pathways were biosynthesis of amino acids, plant hormone signal transduction, aminoacyltRNA biosynthesis, ribosome, phenylpropanoid biosynthesis, starch and sucrose metabolism, and glycolysis (Additional file 2: Table S9).

Based on these analyses, we find that the ABA, ETH biosynthesis and signal transduction, and starch and sucrose metabolism pathways were significantly enriched in the switchgrass lncRNA annotation, GO analysis, and pathway enrichment during multiple dehydration stresses. These pathways probably play important roles in the dehydration stress response, and we next identified related lncRNAs and genes.
LncRNAs involved in plant hormone biosynthesis and signal transduction $A B A$ biosynthesis and signal transduction

ABA biosynthesis and signal transduction were enriched in the differentially expressed lncRNA annotation (Additional file 2: Table S7), GO, and pathway analysis (Additional file 2: Table S7, S8). ABA is the most important plant hormone expressed in response to drought stress, as it is involved in signal perception and transduction, stomatal closure, and osmotic adjustment $[11,46,61]$. In Arabidopsis, NCEDs are the key enzymes in ABA biosynthesis, and abscisic-aldehyde oxidases (AAOs) catalyze the last step of this process [47]. During ABA signal

Table 1 Statistic data of annotation IncRNAs and genes

\begin{tabular}{lllllll}
\hline Annotation Type & $\begin{array}{l}\text { Number of } \\
\text { IncRNAs }\end{array}$ & $\begin{array}{l}\text { Differentially } \\
\text { expressed } \\
\text { IncRNAs }\end{array}$ & $\begin{array}{l}\text { Annotation } \\
\text { genes }\end{array}$ & Expressed genes & $\begin{array}{l}\text { Differentially } \\
\text { expressed } \\
\text { genes (DEGs) }\end{array}$ & $\begin{array}{l}\text { Differentially expressed } \\
\text { IncRNAs annotated } \\
\text { with DEGs }\end{array}$ \\
\hline $\begin{array}{l}\text { antisense-mRNA } \\
\text { Up/Down Stream }\end{array}$ & 2129 & 142 & 2018 & 701 & 63 & 13 \\
$\begin{array}{l}\text { pre-miRNA } \\
\text { Known:9 Novel:47 }\end{array}$ & 299 & 1556 & 988 & 112 & 26 \\
\hline
\end{tabular}




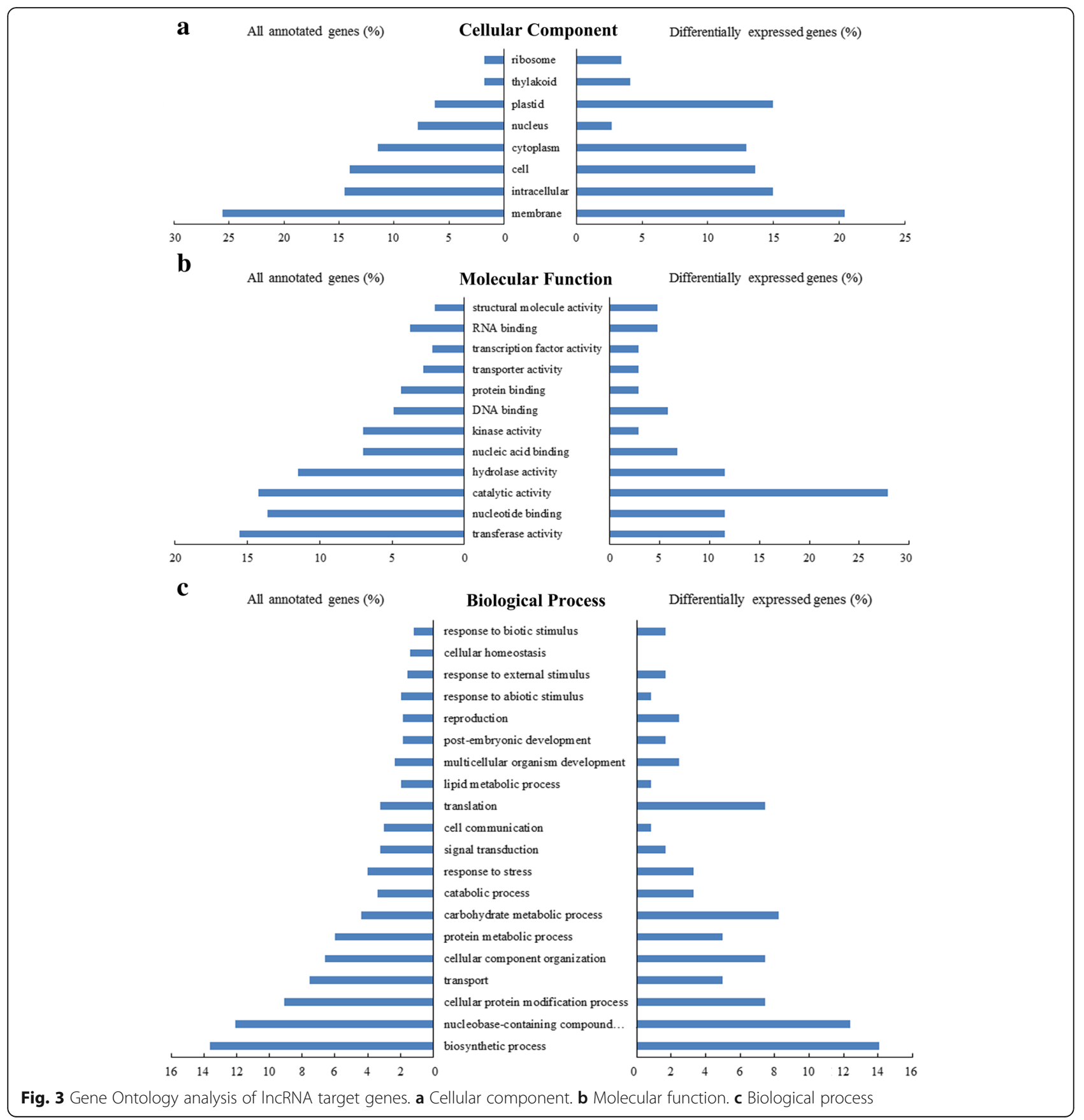

transduction, clade A protein phosphatase 2C (PP2CA) enzymes play important roles in ABA signaling and respond positively to ABA level increases or stressinduced ABA biosynthesis $[62,63]$. In this study, an lncRNA (XLOC_053020) located 1229 bp upstream of Pavir.Ia01153, an ortholog of AtNCED3 (AT3G14440, encoding the rate-limiting enzyme of ABA biosynthesis), was upregulated significantly in D1 and D2. Meanwhile, Pavir.Ia01153 was also upregulated (Fig. 4a, b; Additional file 2: Table S10). XLOC_014465 and its antisense gene (Pavir.Bb00347), an ortholog of $A A O 1$, were upregulated in D1 and D2. Furthermore, the PP2CA gene Pavir.Eb01847 and its upstream lncRNA XLOC_ 033252 were both upregulated in D1 and D2 (Fig. 4; Additional file 2: Table S10). These data suggest that ABA biosynthesis and signal transduction were significantly enhanced during multiple dehydration stresses in switchgrass, especially in D2, and the lncRNAs XLOC_053020, XLOC_014465, and XLOC_033252 probably have important functions in stress-induced responses. 

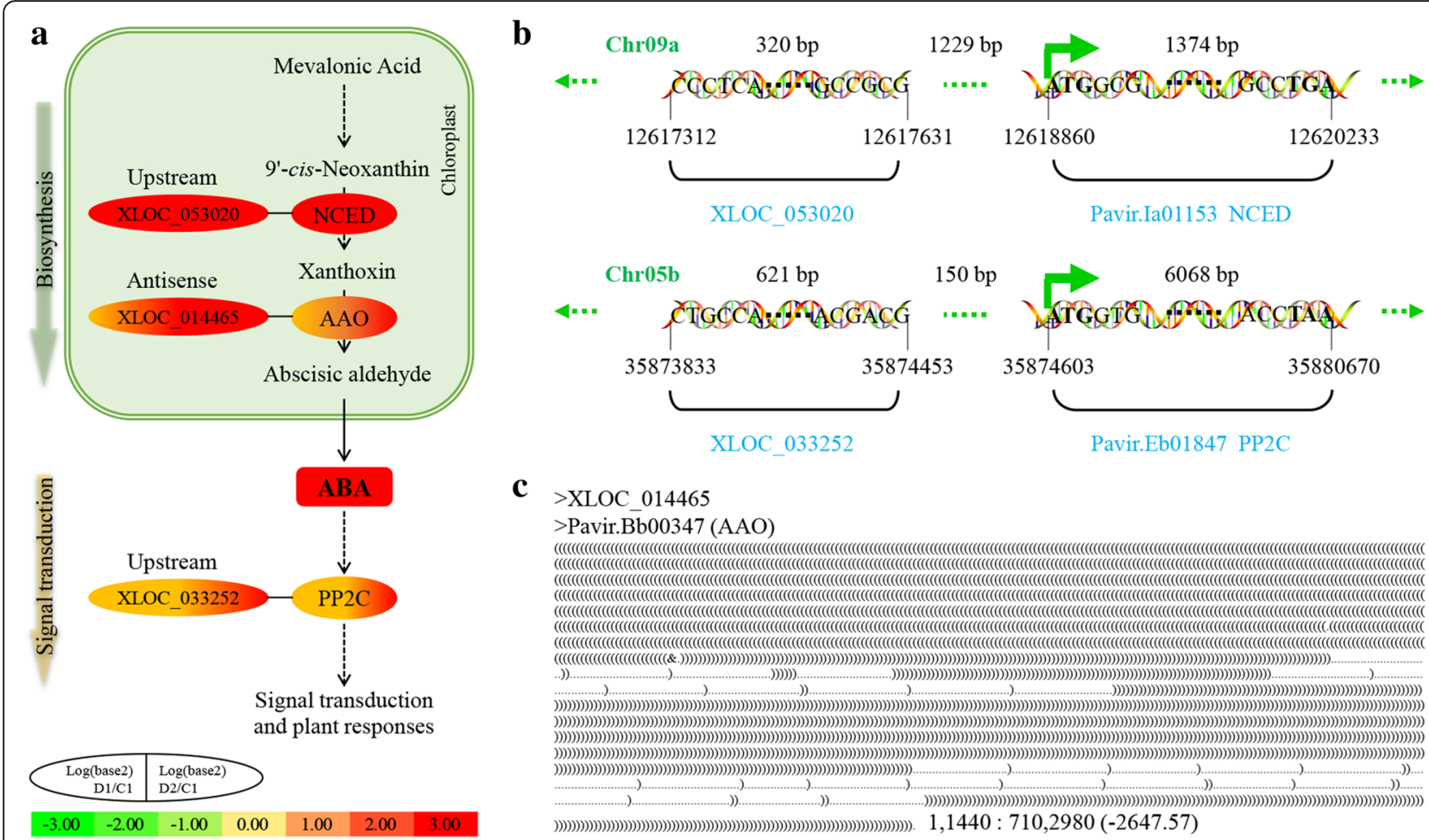

c

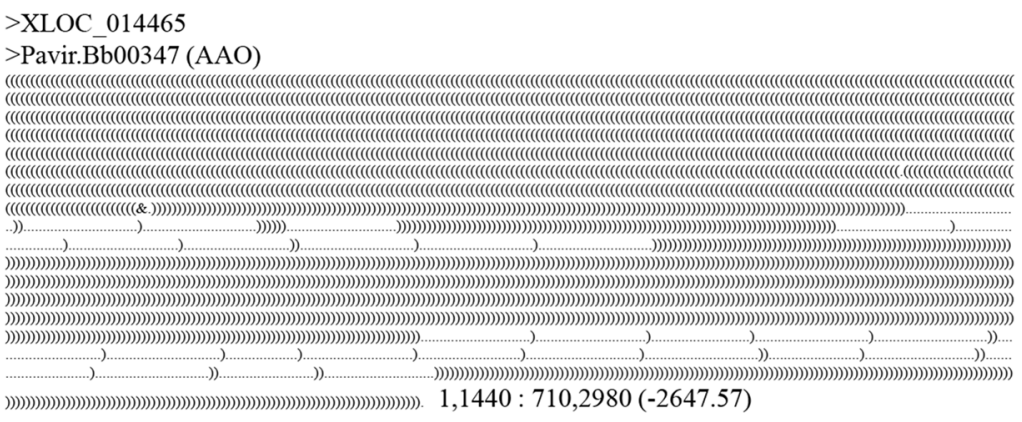

Fig. 4 ABA metabolism in multiple dehydration stresses. a ABA biosynthesis and signal transduction. b Location of differentially expressed IncRNAs. c Complementary base-pairing between IncRNA and annotated gene. 1, 1440: 710, 2980 (- 2647.57), complementary start, end for gene: start, end for IncRNA (minimum gibbs energy); ABA, abscisic acid; NCED, 9-cis-epoxycarotenoid dioxygenase [EC 1.13.11.51]; AAO, abscisic-aldehyde oxidase [EC:1.2.3.14]; PP2C, protein phosphatase 2C [EC:3.1.3.16]

\section{ETH biosynthesis and signal transduction}

In drought stress, ETH is an important gas hormone, regulating plant growth and senescence [64-66]. In plants, ETH is synthesized from L-methionine, and the rate-limiting enzymes are 1-aminocyclopropane-1-carboxylate synthase (ACS) and aminocyclopropane carboxylate oxidase (ACO) $[67,68]$. After synthesis, ETH acts through ETH receptors (ethylene response, ETRs; ethylene response sensors, ERSs; and ethylene insensitive proteins, EINs) [69] and ethyleneresponsive transcription factors (ERFs) [70-72]. In this study, two orthologs of AtACO5 (AT1G77330), Pavir.J23169 and Pavir.Ca01179, were upregulated in D1 and downregulated in D2. Another ortholog of AtACO4 (AT1G05010), Pavir.J04626, was downregulated in both D1 and D2. Three IncRNAs, XLOC_090250, XLOC_016922, and XLOC_ 067866, are located upstream of the associated genes. The expression patterns of lncRNAs were similar to those of the related genes (Fig. 5; Additional file 2: Table S11). One gene encoding an EIN-like protein, Pavir.J10665, was upregulated in D1 and downregulated in D2. Its antisense lncRNA, XLOC_074836, was upregulated in D2 (Fig. 5; Additional file 2: Table S11). These data suggest that ETH biosynthesis and signal transduction were slightly upregulated in D1, but significantly downregulated in D2.

\section{LncRNAs involved in starch and sucrose metabolism}

The starch and sucrose metabolism pathway is involved in photosynthesis, energy utilization, and osmotic adjustment. Beta-amylases (BAMs) are important enzymes with roles in starch degradation and sustained stomatal opening [73, 74], which can be transcriptionally induced by heat or cold stress in Arabidopsis [75]. In switchgrass under dehydration stress, one ortholog of AtBAM1/5, Pavir.Ba00729, was significantly downregulated in D1 and D2, and its antisense lncRNA, XLOC_008122, was also downregulated (Fig. 6; Additional file 2: Table S12). These results indicated that Pavir.Ba00729 was suppressed under water-deficit stress, and therefore suppressed stomatal opening.

Under normal conditions, starch is degraded to glucose1-phosphate by plastidic alpha-glucan phosphorylase (PHS) [76], and then indirectly converted to trehalose-6phosphate (T-6-P) and trehalose by trehalose phosphatase (TPP) and trehalose phosphate synthase (TPS), respectively [77]. Trehalose has important roles in osmotic adjustment [46]. T-6-P is implicated in the regulation of sugar metabolism [78], and the genes for its synthesis encode TPSs. In Arabidopsis, TPS8-11 belongs to the Class II group, and Class II TPSs are likely regulated by known nutrient signal transduction integrators, such as SnRK1 


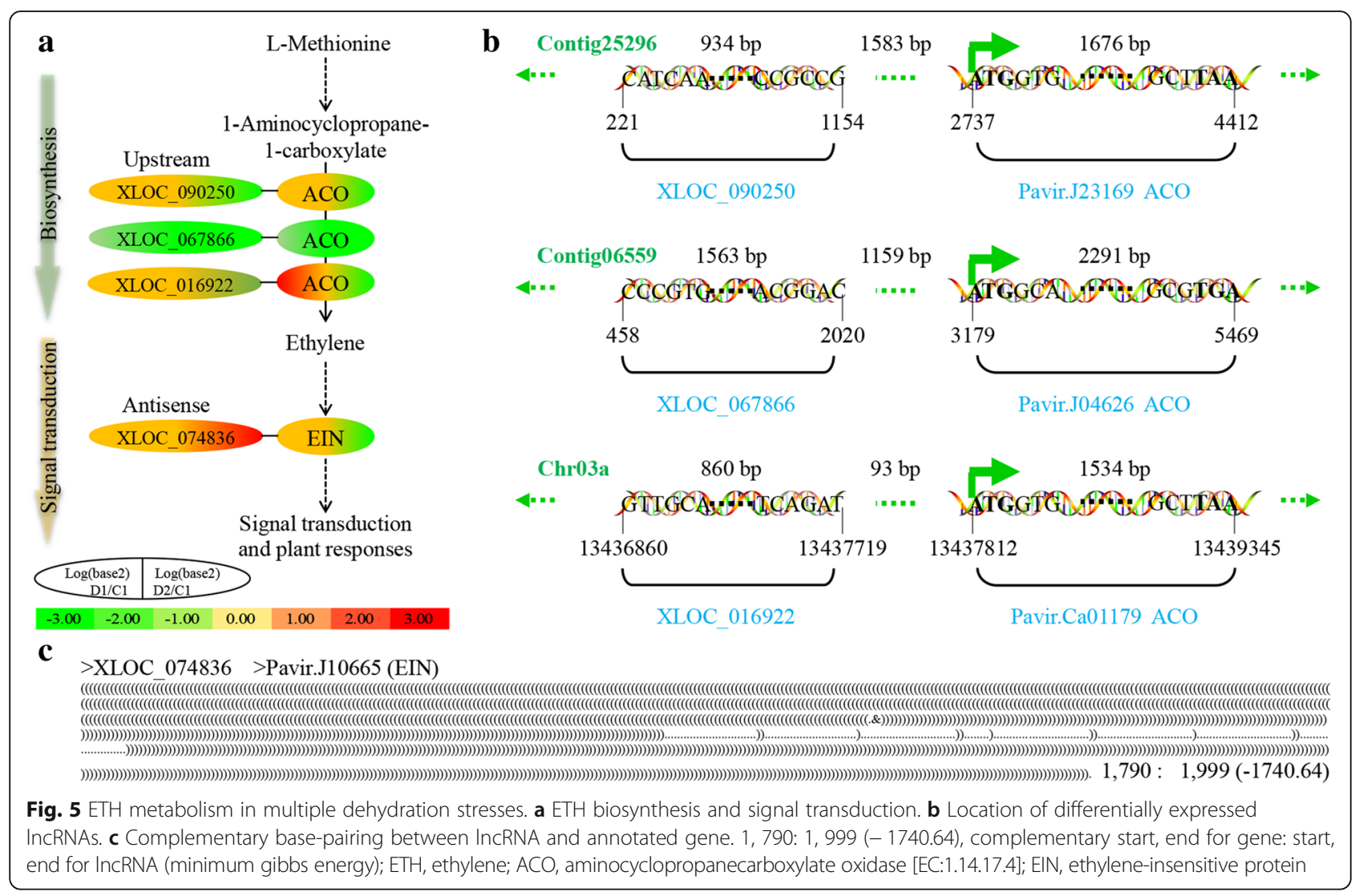

[77]. In switchgrass exposed to multiple dehydration stresses, an ortholog of PHS was upregulated, and its upstream lncRNA, XLOC_081155, was downregulated in D2. An ortholog of AtTPS10, Pavir.Ab03141, and its upstream IncRNA, XLOC_005809, were significantly upregulated, especially in D2 (Fig. 6; Additional file 2: Table S12). These results demonstrate that the starch and sucrose metabolism pathway was altered during dehydration stresses, and that the biosynthesis of T-6-P and trehalose was enhanced, improving sugar metabolism, signal transduction, and osmotic adjustment.

\section{Verification of IncRNAs and ABA metabolism via quantitative real-time PCR (qRT-PCR) and hormone determination}

The RNA-seq results were validated using qRT-PCR in a previous study (Additional file 1: Figure S3). In this study, we quantified the expression of two lncRNAs and three genes involved in ABA biosynthesis and signal transduction, as well as two dehydration stress memory lncRNAs. The expression of all seven transcripts was consistent with transcriptomic data (Fig. 7), indicating that analysis based on transcriptomic data is reliable for determining the response network of switchgrass under multiple dehydration stresses.
We further verified the ABA biosynthesis and signal transduction pathway at the transcriptional and physiological levels. The dynamic change in ABA concentration in leaves was determined using HPLC-MS. The results indicated that ABA accumulated significantly during D1, and increased continuously in R1 and D2 (Fig. 7d). Based on this as well as RNA-seq data and qRT-PCR results, we determined that the upstream IncRNA (XLOC_053020) and orthologs (Pavir.Ia01153 and Pavir.J24772) of the ratelimiting enzyme (NCED), ABA accumulation in leaves, and downstream genes of ABA signal transduction (ABA responsive element binding factor, Pavir.Aa00597 and Pavir. J00256) were upregulated in switchgrass under dehydration stresses, especially in D2 (Fig. 4; Fig. 7; Additional file 2: Table S10). These data indicate that ABA biosynthesis and signal transduction were strongly enhanced during repeated dehydration stresses in switchgrass.

\section{Dehydration stress memory IncRNAs in switchgrass}

During the first round of dehydration stress (D1), 183 and 134 lncRNAs were upregulated and downregulated, respectively, while these numbers increased to 521 and 516 in the second dehydration stress (D2) (Fig. 8a, b). This result indicated that the dehydration stress responses in D1 and D2 differed greatly. In this study, we identified 

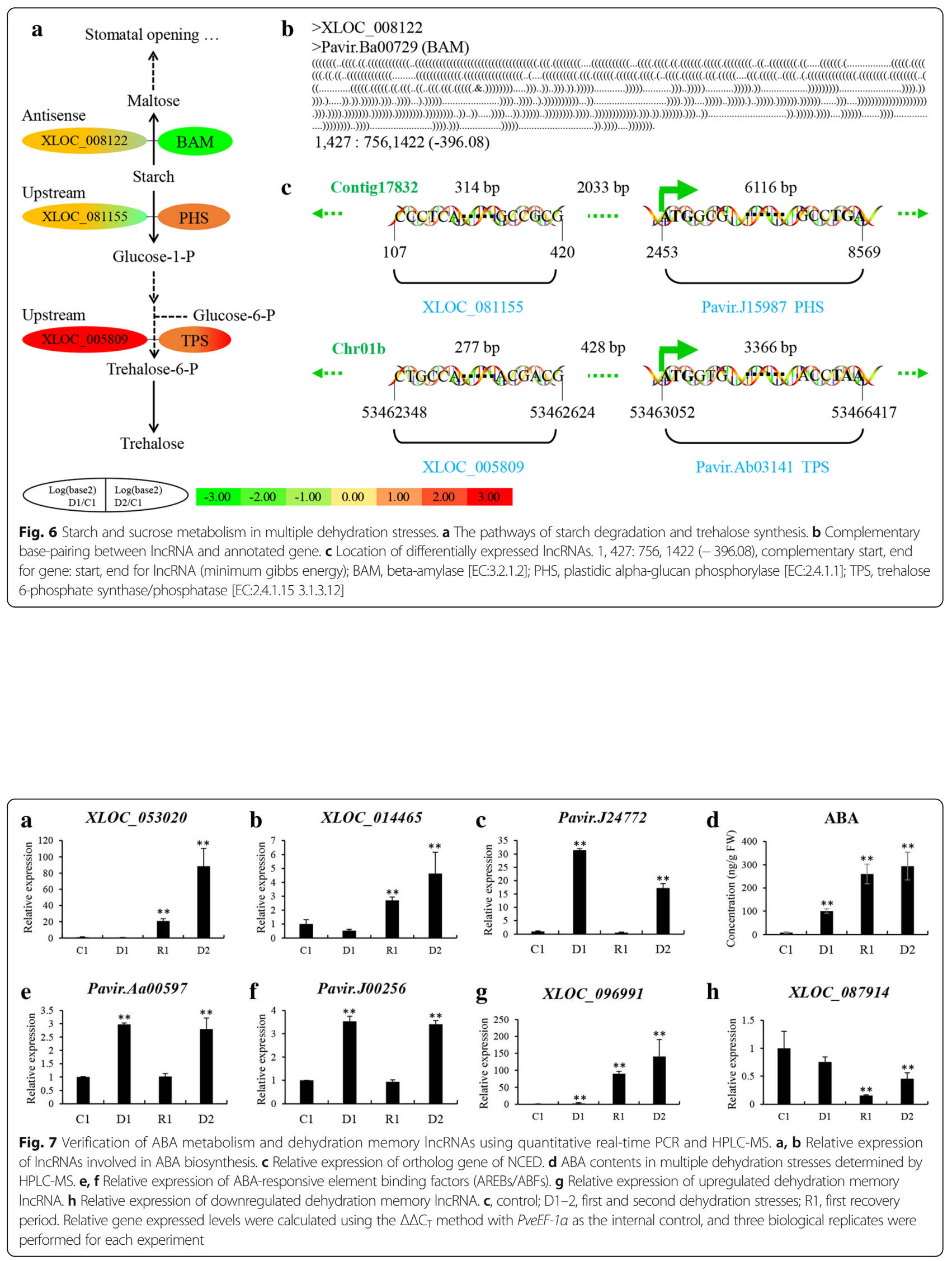

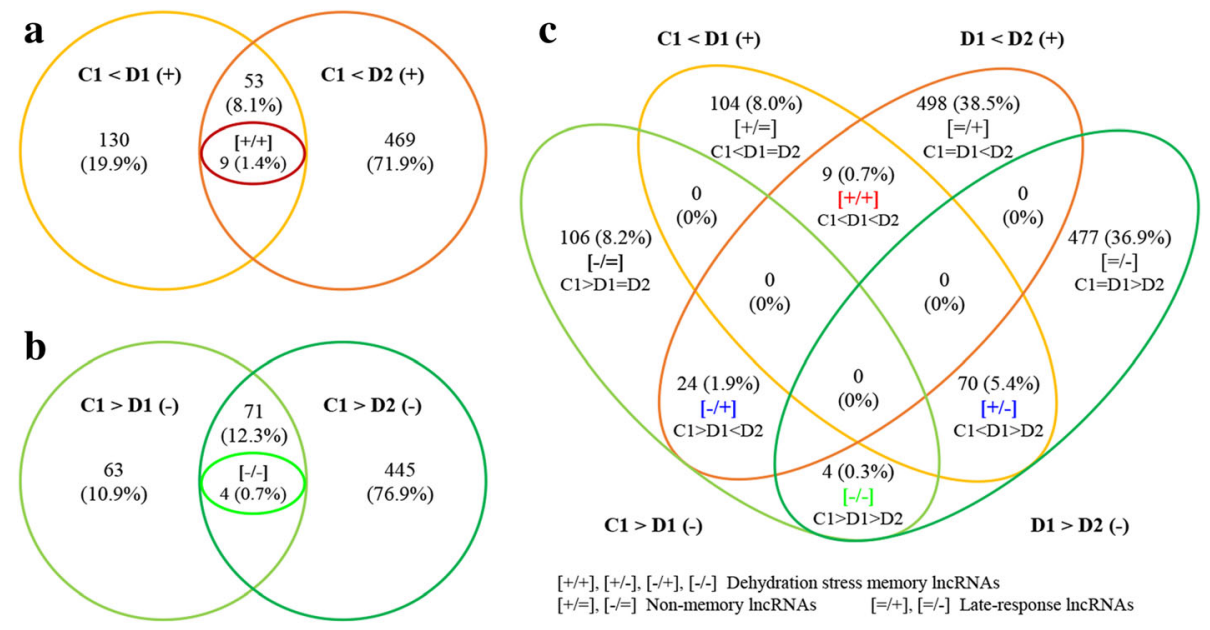

$[=/+],[/ /]$ Late-response IncRNAs

d

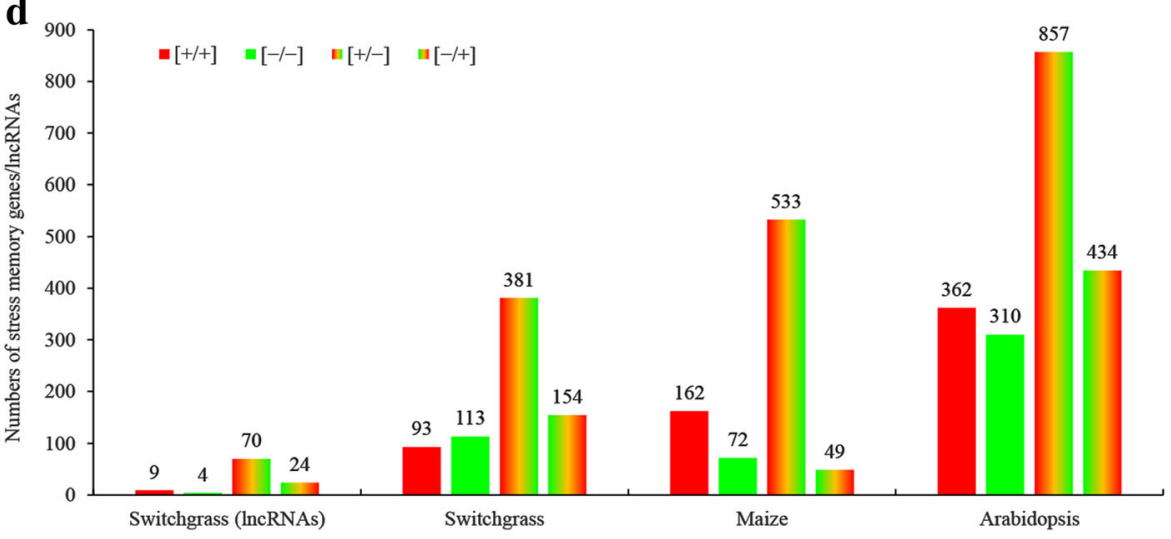

Fig. 8 Identification of dehydration memory IncRNAs in switchgrass, and the compare of response numbers to multiple dehydration stress in switchgrass, maize and Arabidopsis. $\mathbf{a}$, $\mathbf{b}$ Venn diagrams of differentially expressed genes in D1 and D2. c Venn diagrams of different types of dehydration memory genes. $\mathbf{d}$ The compare of response numbers to multiple dehydration stress in switchgrass, maize and Arabidopsis. c, control; D1-2, the first and second dehydration stresses; " + ", "-" and " $=$ " denote up-regulated genes, down-regulated genes, and genes with no significant changes in expression, respectively

dehydration stress memory lncRNAs in switchgrass using screening methods for dehydration stress memory genes reported in Arabidopsis and maize [1,3]. These genes were identified through comparison of fold changes in expression between D1/C1 and D2/D1. LncRNAs that were upregulated, downregulated, and exhibited no significant change in expression are indicated by the symbols "+", "-", and "=", respectively. Nine IncRNAs were identified as $[+/+]$ memory type lncRNAs, meaning that these IncRNAs were upregulated between D1 and $\mathrm{C} 1$ and also between D2 and D1 (Fig. 8c). Similarly, the numbers of $[+/-],[-/+]$, and $[-/-]$ lncRNAs were 70,24 , and 4 , respectively (Fig. 8c, d). Most dehydration stress memory lncRNAs (76.6\%) were not annotated, and thus their functions remain unknown (Additional files 2: Table S1).

\section{Discussion}

Under natural conditions, plants are frequently subjected to dehydration stress due to vapor pressure deficit or soil drought. They are exposed to repeated dehydration stresses throughout their lifecycle, often in quick succession. When the quantity of water lost from leaves through transpiration is greater than the water taken up, plants will suffer from dehydration stress during the daytime. At night, they will recover, but may suffer from dehydration stress again the next day. In the process of evolution, plants have developed dehydration stress memory to adapt to repetitive dehydration stresses. This phenomenon was discovered in Arabidopsis [1, 2], then identified in maize [3]. In stress memory, plants improve their survival rates by rapidly and strongly responding to dehydration stress. Previous studies showed that dehydration stress memory is related to chromatin methylation (especially histone methylation) [2, 8, 9], and lncRNA plays important roles in chromatin methylation and dehydration stress responses [12, 13, 21, 31]. Therefore, we imitated the diurnal cycle of dehydration stress in this study, then constructed IncRNA and mRNA 
libraries, and annotated, identified, and verified lncRNAs involved in multiple dehydration stresses.

LncRNA was annotated by scanning 2000 bp upstream or downstream of genes based on the switchgrass genomic database [50-52], and then analyzing complementary base-pairing between antisense lncRNAs and mRNAs using RNAplex software [57]. In this study, 4554 lncRNAs were annotated, and 9.7\% (441) of these were differentially expressed (Table 1; Fig. 1c). We analyzed the functions of the predicted target genes of all lncRNAs as well as differentially expressed lncRNAs. GO and pathway enrichment analysis showed that ABA and ethylene biosynthesis, signal transduction, and starch and sucrose metabolism were significantly enriched under repetitive dehydration stresses (Fig. 3; Additional file 2: Table S9). In addition, when the above pathways were analyzed, we found that most functional lncRNAs were located upstream of genes, and $85.7 \%$ had similar expression patterns with their downstream genes (Figs. 4-6; Additional file 2: Tables S10-12). The sequence $2000 \mathrm{bp}$ upstream of a target gene is the promoter region, and therefore we inferred that these IncRNAs functioned by interacting with the promoter, cis-acting elements, or other regulatory activities, and thus influenced the transcription of downstream genes [15, 50-52].

To date, ABA is considered the most important hormone involved in plant drought stress responses, and plant drought resistance can be improved significantly by increasing $A B A$ biosynthesis or signal transduction, such as enhancing ABA receptors [79, 80]. In our study, the orthologs of the rate-limiting enzyme of ABA biosynthesis, Pavir.Ia01153 and Pavir.J24772, were significantly upregulated in D1 and D2 (Figs. 4, 7). The lncRNA XLOC_053020, located 1229 bp upstream of Pavir.Ia01153, was upregulated in D1 and D2 (Figs. 4, 7; Additional file 2: Table S10). The signal transduction factors ABF (Pavir.Aa00597, Pavir.J00256) and PP2C (Pavir.Eb01847) were also upregulated during repeated dehydration stresses. The lncRNA XLOC_033252, located 150 bp upstream of Pavir.Eb01847, has the same expression pattern as Pavir.Eb01847 (Fig. 4). The expression levels of these key genes and lncRNAs were verified using qRT-PCR, and the dynamic change in ABA levels was also determined with HPLC-MS (Figs. 4, 7). These data demonstrated that ABA biosynthesis and signal transduction were significantly enhanced during multiple dehydration stresses, and thus the related lncRNAs likely played important roles in these processes. Enhanced ABA metabolism will result in changes in stomatal closure, osmotic adjustment, or metabolic pathways [46, 61].

In contrast to ABA metabolism, ETH biosynthesis and signal transduction were weakened, especially in D2. In Arabidopsis, many key enzymes and factors of this pathway respond to hyperosmotic stress, such as ACOs,
ACSs, ERFs, RTRs, ERSs, and EINs. For example, TaACO1 (wheat) negatively regulates salinity stress in Arabidopsis [81], and three ACO genes, two ETR genes, and four EIN genes were significantly upregulated in physic nut leaves under severe drought stress [82]. In this study, three ACO ortholog genes and one EIN ortholog were downregulated in D2, three lncRNAs located upstream of ACO genes were also downregulated in D2, and one antisense lncRNA of an EIN gene was upregulated in D2 (Fig. 5; Additional file 2: Table S11). These results indicated that ETH biosynthesis and signal transduction were downregulated in D2, demonstrating that switchgrass plants adapted rapidly to repeated dehydration stress in D2. The decrease in ETH is beneficial to plant growth and suppresses leaf senescence [66, 83]. In addition, the differential expression patterns of upstream and antisense lncRNAs with target genes indicated differing action modes of upstream lncRNAs and antisense lncRNAs.

Aside from the plant hormone biosynthesis and signal transduction pathways, starch and sucrose metabolism were also enriched in the functional analysis of lncRNA target genes (Fig. 3; Additional file 2: Table S9). Starch can be degraded to maltose by beta-amylases, and sustains stomatal opening [73, 74]. In this study, an ortho$\log$ of beta-amylase was significantly downregulated in D1 and D2 (Fig. 6; Additional file 2: Table S12), which would promote stomatal closure. On the other hand, starch can be degraded to glucose-1-phosphate by PHS [76], and then indirectly converted into T-6-P and trehalose by TPP and TPS, respectively [77]. In switchgrass under dehydration stress, orthologs of PHS and TPS were significantly upregulated in D1 and D2, and one lncRNA located $428 \mathrm{bp}$ upstream of the TPS gene was also significantly upregulated. These results suggest that starch metabolism was affected and trehalose biosynthesis was enhanced under dehydration stress, which greatly improved carbohydrate metabolism and osmotic adjustment [46].

Following identification and functional analysis of lncRNAs, we sought transcriptional memory lncRNAs expressed under repetitive dehydration stresses. Using a method and threshold values reported for Arabidopsis and maize [1,3], we identified 107 dehydration memory lncRNAs, including 9 upregulated memory $([+/+])$ lncRNAs, 4 downregulated memory ([-/-]) lncRNAs, 70 $[+/-]$ memory lncRNAs, and $24[-/+]$ memory lncRNAs (Fig. 8c, d; Additional file 2: Table S1). Remarkably, the number of [+/-] lncRNAs (65.4\%) was significantly greater than the other three types, and this phenomenon is apparent in the ratios of dehydration stress memory genes in switchgrass (51\%), Arabidopsis (44\%), and maize (65\%) (Fig. 8c, d; Additional file 2: Table S13). The mechanism of this phenomenon is unknown, and $76.6 \%$ of the dehydration stress memory lncRNAs were not 
annotated, and thus their functions remain unknown (Additional file 2: Table S1). High-throughput RNA sequencing may allow elucidation of dehydration memory genes and lncRNAs, and the information acquired in this study provides a strong foundation for analysis of the sophisticated network.

\section{Conclusions}

In this study, switchgrass plantlets of a homogenous genotype were exposed to multiple dehydration stresses. We identified 16,551 lncRNAs, of which 441 were differentially expressed. We annotated 4554 lncRNAs in up/ downstream or complementary base-pairing analysis, while GO and pathway enrichment analysis demonstrated that these lncRNAs were involved in ABA and ETH biosynthesis and signal transduction, as well as starch and sucrose metabolism. Subsequent analysis indicated that $\mathrm{ABA}$ and trehalose were synthesized significantly in D1 and D2, and ABA signal transduction was also enhanced. Meanwhile, ETH biosynthesis and signal transduction was suppressed. Transcriptomic data, including genes involved in ABA metabolism and the associated lncRNAs were verified using qRT-PCR. HPLCMS showed that ABA accumulated significantly during dehydration stress, especially in D2. Furthermore, 307 dehydration stress memory lncRNAs were identified and we found that the ratios of different memory types are similar in switchgrass, Arabidopsis, and maize. In this study, we identified and characterized lncRNAs in switchgrass repetitive dehydration stress, and the IncRNAs and genes identified in this paper provide novel resources for genetic modification of switchgrass and other crops in the Gramineae family, in particular wheat, rice, and maize.

\section{Additional files}

Additional file 1: Figure S1. Overview of the RNA-Seq results and repeatability of different biological replicates. The first eight figures show the proportion of clean reads in the sequenced samples; the next three figures show the repeated expression of genes in two biological replicates; the last eight figures showed the correlations between differentially expressed genes in two biological replicates, and the distributions of upregulated and downregulated genes/IncRNAs in multiple dehydration stresses. C, control; D1 -2 , the first and second dehydration stresses; R1, the first recovery period. Figure S2. Water loss and survive rates in multiple dehydration stresses. A. Water loss from leaves during the first, second and third dehydration stresses. B. Survival rates of trained and non-trained switchgrass. Figure S3. Verification of four types of dehydration memory genes by quantitative real-time PCR. C, control; D1-2, first and second dehydration stresses; R1, first recovery period. Relative gene expressed levels were calculated using the $\Delta \Delta C T$ method with PveEF-1a as the internal control, and three biological replicates were performed for each experiment. (ZIP $1905 \mathrm{~kb}$ )

Additional file 2: Table S1. List of memory IncRNAs. Table S2. Primers used in QRT-PCR. Table S3. Expression summary of different samples and treatments. Table S4. List of differentially expressed IncRNAs. Table S5. LncRNAs annotated by antisense and upstream or downstream. Table $\mathbf{S 6}$ Differentially expressed IncRNAs and the annotated genes. Table S7.
Differentially expressed IncRNAs annotated with differentially expressed genes. Table S8. GO term _ response to stress. Table S9. Top 20 pathway enriched in annotation genes. Table S10. LncRNAs and genes involved in ABA biosynthesis and signal transduction. Table S11. LncRNAs and genes involved in ETH biosynthesis and signal transduction. Table S12. LncRNAs and genes involved in starch and sucrose metabolism. Table S13. Dehydration response and transcriptional memory genes or IncRNAs in switchgrass, maize and Arabidopsis. (ZIP 3778 kb)

\section{Abbreviations}

"-": Downregulated significantly between A and B; "+": Upregulated significantly between $A$ and $B ;$ " $=$ ": No significant change between $A$ and $B$; AAO: Abscisic-aldehyde oxidase; ABA: Abscisic acid;

ACO: Aminocyclopropane carboxylate oxidase; ACS: 1-aminocyclopropane-1carboxylate synthase; AREBs/ABFs: ABA responsive element binding factors; BAM: Beta-amylases; BLAST: Basic local alignment search tool; C1: Control;

D1: The first dehydration stress; D2: The secondary dehydration stress;

EIN: Ethylene insensitive protein; ETH: Ethylene; FPKM: Fragments per kilobase of exon per million fragments mapped; GO: Gene ontology; HPLCMS: High performance liquid chromatography - mass spectrometry; KEGG: Kyoto encyclopedia of genes and genomes; IncRNA: Long non-coding RNA; NCED: 9-cis-epoxycarotenoid dioxygenase; PHS: Plastidic alpha-glucan phosphorylase; PP2C: Protein phosphatase 2C; qRT-PCR: Quantitative realtime PCR; R1: First recovery; SnRK: Serine/threonine-protein kinase SRK; T-6$P$ : Trehalose-6-phosphate; TPS: Trehalose phosphate synthase

\section{Funding}

This research was supported by grants from the National Natural Science Foundation of China (No. 31601370, 31301384, 31371690), China Postdoctoral Science Foundation (No. 171305), PhD Start-up Foundation (Z109021616) and Basic Scientific Research Foundation (Z109021705) of Northwest A\&F University. All these funding play roles in the design of the study and collection, analysis, and in writing the manuscript.

\section{Availability of data and materials}

The datasets analyzed during the current study are available in the Sequence Read Archive (SRA) at NCBI (accession number PRJNA394165) repository, https://trace.ncbi.nlm.nih.gov/Traces/sra/.

\section{Authors' contributions}

YX and FS conceived and designed the experiments. GT and XP carried out the physiological experiments; CZ carried out the molecular biology experiments, analyzed the data and wrote the paper. SL, FS and YX revised the paper. All authors read and approved the final manuscript.

Ethics approval and consent to participate

Not applicable.

Competing interests

The authors declare that they have no competing interests.

\section{Publisher's Note}

Springer Nature remains neutral with regard to jurisdictional claims in published maps and institutional affiliations.

\section{Author details}

${ }^{1}$ College of Agronomy, Northwest A \& F University, Yangling 712100, Shaanxi, China. ${ }^{2}$ Key Laboratory of Wheat Biology and Genetic Breeding, Ministry of Agriculture, Yangling 712100, Shaanxi, China. ${ }^{3}$ College of Plant Protection, Northwest A \& F University, Yangling 712100, Shaanxi, China.

Received: 27 November 2017 Accepted: 22 April 2018

Published online: 04 May 2018

\section{References}

1. Ding Y, Liu N, Virlouvet L, Riethoven JJ, Fromm M, Avramova Z. Four distinct types of dehydration stress memory genes in Arabidopsis thaliana. BMC Plant Biol. 2013;13:229

2. Ding Y, Fromm M, Avramova Z. Multiple exposures to drought 'train' transcriptional responses in Arabidopsis. Nat Commun. 2012;3:740. 
3. Ding $Y$, Virlouvet L, Liu N, Riethoven JJ, Fromm M, Avramova Z. Dehydration stress memory genes of Zea mays; comparison with Arabidopsis thaliana. BMC Plant Biol. 2014;14:141.

4. Walter J, Nagy L, Hein R, Rascher U, Beierkuhnlein C, Willner E, Jentsch A. Do plants remember drought? Hints towards a drought-memory in grasses. Environ Exp Bot. 2011;71:34-40.

5. Ramirez DA, Rolando JL, Yactayo W, Monneveux P, Mares V, Quiroz R. Improving potato drought tolerance through the induction of long-term water stress memory. Plant Sci. 2015;238:26-32.

6. Leufen $G$, Noga $G$, Hunsche M. Drought stress memory in sugar beet: mismatch between biochemical and physiological parameters. J Plant Growth Regul. 2016;35:680-9.

7. Fleta-Soriano E, Pinto-Marijuan M, Munne-Bosch S. Evidence of drought stress memory in the facultative CAM, aptenia cordifolia: possible role of phytohormones. PLoS One. 2015;10:8.

8. Lamke J, Brzezinka K, Altmann S, Baurle I. A hit-and-run heat shock factor governs sustained histone methylation and transcriptional stress memory. EMBO J. 2016;35:162-75.

9. Avramova Z. Transcriptional 'memory' of a stress: transient chromatin and memory (epigenetic) marks at stress-response genes. Plant J. 2015;83:149-59.

10. Liu N, Staswick PE, Avramova Z. Memory responses of jasmonic acidassociated Arabidopsis genes to a repeated dehydration stress. Plant Cell and Environment. 2016;39:2515-29.

11. Virlouvet $L$, Ding $Y$, Fujii $H$, Avramova Z, Fromm M. ABA signaling is necessary but not sufficient for RD29B transcriptional memory during successive dehydration stresses in Arabidopsis thaliana. Plant J. 2014;79:150-61.

12. Wibowo A, Becker C, Marconi G, Durr J, Price J, Hagmann J, Papareddy R, Putra H, Kageyama J, Becker J, et al. Hyperosmotic stress memory in Arabidopsis is mediated by distinct epigenetically labile sites in the genome and is restricted in the male germline by DNA glycosylase activity. elife. 2016;5:e13546

13. Heo JB, Lee YS, Sung S. Epigenetic regulation by long noncoding RNAs in plants. Chromosom Res. 2013;21:685-93.

14. Wang KC, Yang YW, Liu B, Sanyal A, Corceszimmerman R, Chen Y, Lajoie BR, Protacio A, Flynn RA, Gupta RA. A long noncoding RNA maintains active chromatin to coordinate homeotic gene expression. Nature. 2011:472:120-4.

15. Liu J, Wang $\mathrm{H}$, Chua NH. Long noncoding RNA transcriptome of plants. Plant Biotechnol J. 2015;13:319-28.

16. Jin JJ, Liu J, Wang H, Wong L, Chua NH. PLncDB: plant long non-coding RNA database. Bioinformatics. 2013;29:1068-71.

17. Di C, Yuan J, Wu Y, Li J, Lin H, Hu L, Zhang T, Qi Y, Gerstein MB, Guo Y, Lu ZJ. Characterization of stress-responsive InCRNAs in Arabidopsis thaliana by integrating expression, epigenetic and structural features. Plant J. 2014;80: 848-61.

18. Zhu Q-H, Stephen S, Taylor J, Helliwell CA, Wang M-B. Long noncoding RNAs responsive to Fusarium oxysporum infection in Arabidopsis thaliana. New Phytol. 2014;201:574-84

19. Wu J, Okada T, Fukushima T, Tsudzuki T, Sugiura M, Yukawa Y. A novel hypoxic stress-responsive long non-coding RNA transcribed by RNA polymerase III in Arabidopsis. RNA Biol. 2012;9:302-13.

20. Liu J, Jung C, Xu J, Wang H, Deng S, Bernad L, Arenas-Huertero C, Nam-Hai $C$. Genome-wide analysis uncovers regulation of long intergenic noncoding rnas in Arabidopsis. Plant Cell. 2012;24:4333-45.

21. Zhang W, Han ZX, Guo QL, Liu Y, Zheng YX, Wu FL, Jin WB. Identification of maize long non-coding RNAs responsive to drought stress. PLoS One. 2014;9:6

22. Zhao XL, Liu XM, Guo CJ, Gu JT, Xiao K. Identification and characterization of microRNAs from wheat (Triticum aestivum L.) under phosphorus deprivation. J Plant Biochem Biotechnol. 2013;22:113-23.

23. Zhang YC, Liao JY, Li ZY, Yu Y, Zhang JP, Li QF, Qu LH, Shu WS, Chen YQ. Genome-wide screening and functional analysis identify a large number of long noncoding RNAs involved in the sexual reproduction of rice. Genome Biol. 2014;15:12.

24. Chen JH, Quan MY, Zhang DQ. Genome-wide identification of novel long non-coding RNAs in Populus tomentosa tension wood, opposite wood and normal wood xylem by RNA-seq. Planta. 2015;241:125-43.

25. Lu XK, Chen XG, Mu M, Wang JJ, Wang XG, Wang DL, Yin ZJ, Fan WL, Wang S, Guo LX, Ye WW. Genome-wide analysis of long noncoding rnas and their responses to drought stress in cotton (Gossypium hirsutum I.). PLoS One. 2016;11:6

26. Ding J, Lu Q, Ouyang Y, Mao H, Zhang P, Yao J, Xu C, Li X, Xiao J, Zhang Q. A long noncoding RNA regulates photoperiod-sensitive male sterility, an essential component of hybrid rice. Proc Natl Acad Sci U S A. 2012;109:2654-9.
27. Zou CS, Wang QL, Lu CR, Yang WC, Zhang YP, Cheng HL, Feng XX, Prosper MA, Song GL. Transcriptome analysis reveals long noncoding RNAs involved in fiber development in cotton (Gossypium arboreum). Science China-Life Sciences. 2016:59:164-71.

28. Tang W, Zheng Y, Dong J, Yu J, Yue JY, Liu FF, Guo XH, Huang SX, Wisniewski M, Sun JQ, et al. Comprehensive transcriptome profiling reveals long noncoding RNA expression and alternative splicing regulation during fruit development and ripening in kiwifruit (Actinidia chinensis). Front Plant Sci. 2016;7:335.

29. Kwenda S, Birch PRJ, Moleleki LN. Genome-wide identification of potato long intergenic noncoding RNAs responsive to Pectobacterium carotovorum subspecies brasiliense infection. BMC Genomics. 2016;17:614.

30. Xiao H, Yuan Z, Guo D, Hou B, Yin C, Zhang W, Li F. Genome-wide identification of long noncoding RNA genes and their potential association with fecundity and virulence in rice brown planthopper, Nilaparvata lugens. BMC Genomics. 2015;16:749.

31. Wang TZ, Liu M, Zhao MG, Chen R, Zhang WH. Identification and characterization of long non-coding RNAs involved in osmotic and salt stress in Medicago truncatula using genome-wide high-throughput sequencing. BMC Plant Biol. 2015;15:131.

32. Wang D, Qu ZP, Yang L, Zhang QZ, Liu ZH, Do T, Adelson DL, Wang ZY, Searle I, Zhu JK. Transposable elements (TEs) contribute to stress-related long intergenic noncoding RNAs in plants. Plant J. 2017;90:133-46.

33. Wunderlich M, Gross-Hardt R, Schoffl F. Heat shock factor HSFB2a involved in gametophyte development of Arabidopsis thaliana and its expression is controlled by a heat-inducible long non-coding antisense RNA. Plant Mol Biol. 2014;85:541-50.

34. Somleva MN. Switchgrass (Panicum virgatum L.). Methods Mol Biol. 2006; 344:65-73.

35. David K, Ragauskas AJ. Switchgrass as an energy crop for biofuel production: a review of its ligno-cellulosic chemical properties. Energy Environ Sci. 2010;3:1182-90.

36. Mclaughlin SB, Kszos LA. Development of switchgrass (Panicum virgatum ) as a bioenergy feedstock in the United States. Biomass Bioenergy. 2005;28: 515-35.

37. Wu Z, Cao Y, Yang R, Qi T, Hang Y, Lin H, Zhou G, Wang Z-Y, Fu C. Switchgrass SBP-box transcription factors PVSPL1 and 2 function redundantly to initiate side tillers and affect biomass yield of energy crop. Biotechnol Biofuels. 2016;9:101.

38. Hultquist SJ, Vogel KP, Lee DJ, Arumuganathan K, Kaeppler S. Chloroplast DNA and nuclear DNA content variations among cultivars of switchgrass, Panicum virgatum L. Crop Sci. 1996;36:1049-52.

39. Xi YJ, Fu CX, Ge YX, Nandakumar R, Hisano H, Bouton J, Wang ZY. Agrobacterium-mediated transformation of switchgrass and inheritance of the transgenes. Bioenergy Research. 2009;2:275-83.

40. Aimar D, Calafat M, Andrade AM, Carassay L, Bouteau F, Abdala G, Molas ML. Drought effects on the early development stages of Panicum virgatum L.: cultivar differences. Biomass Bioenergy. 2014;66:49-59.

41. Meyer E, Aspinwall MJ, Lowry DB, Palacio-Mejia JD, Logan TL, Fay PA, Juenger TE. Integrating transcriptional, metabolomic, and physiological responses to drought stress and recovery in switchgrass (Panicum virgatum L.). BMC Genomics. 2014;15:527.

42. Liu Y, Zhang X, Tran H, Shan L, Kim J, Childs K, Ervin EH, Frazier T, Zhao B. Assessment of drought tolerance of 49 switchgrass (Panicum virgatum) genotypes using physiological and morphological parameters. Biotechnol Biofuels. 2015;8:152.

43. Xie FL, Stewart CN, Taki FA, He QL, Liu HW, Zhang BH. High-throughput deep sequencing shows that microRNAs play important roles in switchgrass responses to drought and salinity stress. Plant Biotechnol J. 2014;12:354-66.

44. Sun $G L$, Stewart $C N$, Xiao P, Zhang BH. Microrna expression analysis in the cellulosic biofuel crop switchgrass (Panicum virgatum) under abiotic stress. PLoS One. 2012;7:3.

45. Shinozaki K, Yamaguchi-Shinozaki K. Gene networks involved in drought stress response and tolerance. J Exp Bot. 2007:58:221-7.

46. Krasensky J, Jonak C. Drought, salt, and temperature stress-induced metabolic rearrangements and regulatory networks. J Exp Bot. 2012;63: 1593-608.

47. Behnam B, luchi S, Fujita M, Fujita Y, Takasaki H, Osakabe Y, YamaguchiShinozaki K, Kobayashi M, Shinozaki K. Characterization of the promoter region of an Arabidopsis gene for 9-cis-epoxycarotenoid dioxygenase involved in dehydration-inducible transcription. DNA Res. 2013;20:315-24. 
48. Pizzio GA, Rodriguez $L$, Antoni R, Gonzalez-Guzman M, Yunta C, Merilo E, Kollist H, Albert A, Rodriguez PL. The PYL4 A194T mutant uncovers a key role of PYR1-like4/protein Phosphtase 2CA interaction for abscisic acid signaling and plant drought resistance. Plant Physiol. 2013;163:441-55.

49. Choi H, Hong J, Ha J, Kang J, Kim SY. ABFs, a family of ABA-responsive element binding factors. J Biol Chem. 2000;275:1723-30.

50. Yazgan O, Krebs JE. Noncoding but nonexpendable: transcriptional regulation by large noncoding RNA in eukaryotes. Biochemistry \& Cell Biology. 2007;85:484

51. Mercer TR, Dinger ME, Mattick JS. Long non-coding RNAs: insights into functions. Nat Rev Genet. 2009;10:155.

52. Carninci P, Kasukawa T, Katayama S, Gough J, Frith MC, Maeda N, Oyama R, Ravasi T, Lenhard B, Wells C, et al. The transcriptional landscape of the mammalian genome. Science. 2005;309:1559-63.

53. Carrieri C, Cimatti L, Biagioli M, Beugnet A, Zucchelli S, Fedele S, Pesce E, Ferrer I, Collavin L, Santoro C. Long non-coding antisense RNA controls Uchl1 translation through an embedded SINEB2 repeat. Nature. 2012;491: 454-7.

54. Xu K, Sun F, Wang YW, Chai G, Shi L, Liu S, Xi Y. De novo assembly and transcriptome analysis of two contrary tillering mutants to learn the mechanisms of tillers outgrowth in switchgrass (Panicum virgatum L.). Front Plant Sci. 2015;6:749

55. Trapnell C, Hendrickson DG, Sauvageau M, Goff L, Rinn JL, Pachter L. Differential analysis of gene regulation at transcript resolution with RNA-seq. Nat Biotechnol. 2013:31:46.

56. Casler MD, Tobias CM, Kaeppler SM, Buell CR, Wang ZY, Cao PJ, Schmutz J, Ronald P. The switchgrass genome: tools and strategies. Plant Genome. 2011:4:273-82.

57. Tafer $\mathrm{H}$, Hofacker IL. RNAplex: a fast tool for RNA-RNA interaction search. Bioinformatics. 2008:24:2657-63.

58. McCarthy FM, Wang N, Magee GB, Nanduri B, Lawrence ML, Camon EB, Barrell DG, Hill DP, Dolan ME, Williams WP. AgBase: a functional genomics resource for agriculture. BMC Genomics. 2006;7:229.

59. Gimeno J, Eattock N, Deynze AV, Blumwald E. Selection and validation of reference genes for gene expression analysis in switchgrass (Panicum virgatum) using quantitative real-time RT-PCR. PLoS One. 2014;9:e91474.

60. Duncan DB. Multiple range and multiple F tests. Biometrics. 1955;11:1-42.

61. Seki M, Umezawa T, Urano K, Shinozaki K. Regulatory metabolic networks in drought stress responses. Curr Opin Plant Biol. 2007;10:296-302.

62. Fuchs S, Grill E, Meskiene I, Schweighofer A. Type 2 C protein phosphatases in plants. FEBS J. 2013;280:681.

63. Fujita Y, Fujita M, Shinozaki K, Yamaguchishinozaki K. ABA-mediated transcriptional regulation in response to osmotic stress in plants. J Plant Res. 2011;124:509.

64. Seki M, Narusaka M, Ishida J, Nanjo T, Fujita M, Oono Y, Kamiya A, Nakajima M, Enju A, Sakurai T, et al. Monitoring the expression profiles of 7000 Arabidopsis genes under drought, cold and high-salinity stresses using a full-length CDNA microarray. Plant J. 2002;31:279-92.

65. Wilkinson S, Davies WJ. Drought, ozone, ABA and ethylene: new insights from cell to plant to community. Plant Cell and Environment. 2010;33:510-25.

66. Wang YH, Wan LY, Zhang LX, Zhang ZJ, Zhang HW, Quan RD, Zhou SR, Huang RF. An ethylene response factor OsWR1 responsive to drought stress transcriptionally activates wax synthesis related genes and increases wax production in rice. Plant Mol Biol. 2012;78:275-88.

67. Liang X, Abel S, Keller JA, Shen NF, Theologis A. The 1-aminocyclopropane1-carboxylate synthase gene family of Arabidopsis thaliana. Proc Natl Acad Sci U S A. 1992:89:11046-50.

68. Babula D, Misztal LH, Jakubowicz M, Kaczmarek M, Nowak W, Sadowski J. Genes involved in biosynthesis and signalisation of ethylene in Brassica oleracea and Arabidopsis thaliana: identification and genome comparative mapping of specific gene homologues. Theor Appl Genet. 2006;112:410-20.

69. Liu Q, Wen CK. Arabidopsis ETR1 and ERS1 differentially repress the ethylene response in combination with other ethylene receptor genes. Plant Physiol. 2012:158:1193-207.

70. Guzman P, Ecker JR. Exploiting the triple response of Arabidopsis to identify ethylene-related mutants. Plant Cell. 1990;2:513-23.

71. Zhu Z, Guo H. Genetic basis of ethylene perception and signal transduction in Arabidopsis. J Integr Plant Biol. 2008;50:808-15.

72. Zhang L, Li Z, Quan R, Li G, Wang R, Huang R. An AP2 domain-containing gene, ESE1, targeted by the ethylene signaling component EIN3 is important for the salt response in Arabidopsis. Plant Physiol. 2011;157:854-65.
73. Zanella M, Borghi GL, Pirone C, Thalmann M, Pazmino D, Costa A, Santelia D, Trost P, Sparla F. Beta-amylase 1 (BAM1) degrades transitory starch to sustain proline biosynthesis during drought stress. J Exp Bot. 2016;67:1819-26.

74. Valerio C, Costa A, Marri L, Issakidis-Bourguet E, Pupillo P, Trost P, Sparla F. Thioredoxin-regulated beta-amylase (BAM1) triggers diurnal starch degradation in guard cells, and in mesophyll cells under osmotic stress. J Exp Bot. 2011;62:545-55

75. Monroe JD, Storm AR, Badley EM, Lehman MD, Platt SM, Saunders LK, Schmitz JM, Torres CE. $\beta$-Amylase1 and $\beta$-Amylase3 are plastidic starch hydrolases in Arabidopsis that seem to be adapted for different thermal, $\mathrm{pH}$, and stress conditions. Plant Physiol. 2014;166:1748.

76. Malinova I, Mahlow S, Alseekh S, Orawetz T, Fernie AR, Baumann O, Steup M, Fettke J. Double knockout mutants of Arabidopsis grown under normal conditions reveal that the plastidial phosphorylase isozyme participates in transitory starch metabolism. Plant Physiol. 2014;164:907-21.

77. Schluepmann H, Paul M. Trehalose metabolites in Arabidopsis-elusive, active and central. The Arabidopsis book. 2009;7:-e0122.

78. Eastmond PJ, Li Y, Graham IA. Is trehalose-6-phosphate a regulator of sugar metabolism in plants? J Exp Bot. 2003;54:533-7.

79. Cao MJ, Zhang YL, Liu X, Huang H, Zhou XE, Wang WL, Zeng A, Zhao CZ, Si $\mathrm{T}$, Du JM, et al. Combining chemical and genetic approaches to increase drought resistance in plants. Nat Commun. 2017:8:12.

80. Park SY, Peterson FC, Mosquna A, Yao J, Volkman BF, Cutler SR. Agrochemical control of plant water use using engineered abscisic acid receptors. Nature. 2015;520:545-8.

81. Chen DH, Ma XY, Li CL, Zhang W, Xia GM, Wang M. A wheat aminocyclopropane1-carboxylate oxidase gene, TaACO1, negatively regulates salinity stress in Arabidopsis thaliana. Plant Cell Rep. 2014;33:1815-27.

82. Zhang C, Zhang L, Zhang S, Zhu S, Wu P, Chen Y, Li M, Jiang H, Wu G. Global analysis of gene expression profiles in physic nut (Jatropha curcas L.) seedlings exposed to drought stress. BMC Plant Biol. 2015;15:17.

83. Beguerisse-Diaz M, Hernandez-Gomez MC, Lizzul AM, Barahona M, Desikan $R$. Compound stress response in stomatal closure: a mathematical model of ABA and ethylene interaction in guard cells. BMC Syst Biol. 2012;6:146.

\section{Ready to submit your research? Choose BMC and benefit from:}

- fast, convenient online submission

- thorough peer review by experienced researchers in your field

- rapid publication on acceptance

- support for research data, including large and complex data types

- gold Open Access which fosters wider collaboration and increased citations

- maximum visibility for your research: over $100 \mathrm{M}$ website views per year

At BMC, research is always in progress.

Learn more biomedcentral.com/submissions 